\title{
Precocious gut maturation and immune cell expansion by single dose feeding the lectin phytohaemagglutinin to suckling rats
}

\author{
Olena Prykhod'ko*, Olexandr Fed'kiv, Ann Linderoth, Stefan G. Pierzynowski and Björn R. Weström \\ Department of Cell and Organism Biology, Lund University, Helgonavägen 3B, SE-223 62 Lund, Sweden
}

(Received 29 February 2008 - Revised 5 June 2008 - Accepted 11 June 2008 - First published online 22 July 2008)

\begin{abstract}
The dietary lectin phytohaemagglutinin (PHA) induces gut growth and precocious maturation in suckling rats after mucosal binding. The present study investigated the dose range in which PHA provokes gut maturation and if it coincided with immune activation. Suckling rats, aged $14 \mathrm{~d}$, were orogastrically fed a single increasing dose of PHA: 0 (control), 2, 10, 50 or $250 \mu \mathrm{g} / \mathrm{g}$ body weight (BW) in saline. The effect on gut, lymphoid organs and appearance of $\mathrm{CD}^{+}$(T-lymphocyte) and $\mathrm{CD} 19^{+}$(B-lymphocyte) cells in the small-intestinal mucosa was studied at $12 \mathrm{~h}$ (acute) and $3 \mathrm{~d}$ (late phase) after treatment. The low PHA doses $(2$ and $10 \mu \mathrm{g} / \mathrm{g} \mathrm{BW})$ induced intestinal hyperplasia without mucosal disarrangement but did not provoke gut maturation. Only the high PHA doses (50 and $250 \mu \mathrm{g} / \mathrm{g} \mathrm{BW})$ temporarily disturbed the intestinal mucosa with villi shortening and decrease in disaccharidase activities, and later after $3 \mathrm{~d}$ provoked precocious maturation, resulting in an increase in maltase and sucrase activities and decrease in lactase activity and disappearance of the fetal vacuolated enterocytes in the distal small intestine. Exposure to the high, but not to the low, PHA doses increased the number of mucosal $\mathrm{CD} 19^{+}$and $\mathrm{CD}^{+}$cells in the small intestine after $12 \mathrm{~h}$, a finding also observed in untreated weaned rats aged 21-28d. In conclusion, there was a dose-related effect of PHA on gastrointestinal growth and precocious maturation that coincided with a rapid expansion of mucosal B- and T-lymphocytes, indicating a possible involvement of the immune system in this process.
\end{abstract}

Gastrointestinal tract: Disaccharidases: B- and T-lymphocytes: Phytohaemagglutinin

In mammalian species, postnatal maturation of the digestive tract is an important physiological event that allows the young to adapt at first to the intake of mother's milk and eventually to the change from milk to solid food. This ontogenetic process is characterised by rapid growth and vast structural and functional changes of the gastrointestinal (GI) tract, especially at weaning ${ }^{(1-4)}$. In parallel with digestive development, a postnatal immunological adaptation to the new dietary and microbial environment also occurs ${ }^{(5,6)}$. The gut-associated immune system is immature at birth and the intestine contains only small numbers of mucosal lamina propria and intra-epithelial lymphocytes, but their amount increases with age ${ }^{(6,7)}$. In fact, it has been hypothesised that the physiological inflammation seen at weaning, with an increase in the number of immune cells and the subsequent epithelial crypt hyperplasia, is caused by the antigenic stimulation during this phase ${ }^{(8-10)}$.

In previous studies using suckling animals, precocious gut maturation was induced by enteral exposure to the lectin phytohaemagglutinin (PHA) obtained from red kidney beans ${ }^{(11-14)}$. It was shown that the binding of PHA to the small-intestinal epithelium was followed by an early temporary mucosal disturbance with a rapid increase in crypt cell proliferation and later by the appearance of a more mature gut epithelium, characterised by adult-like mucosal disaccharidase activities, reduced macromolecular absorption capacity and loss of the vacuolated fetal-type enterocytes. Furthermore,
PHA exposure stimulated pancreas growth and altered stomach function with increased hydrochloric acid secretion, changes that all normally occur during natural weaning. Based on these results, PHA has been suggested as a dietary inducer of maturation for young animals having an immature gut, for example, pre-weaning piglets, to accelerate the gut maturation and to reduce post-weaning problems ${ }^{(11,15)}$, but the mechanism of the action of PHA, however, is still poorly understood.

Previous studies have indicated that PHA could act via several possible pathways. Thus, after binding, PHA might affect the enterocytes directly and thereby induce hyperplasic growth and maturation of the intestine through local effects. In addition, PHA may stimulate systemic effects mediated by the release of gut peptide hormones, such as cholecystokinin, which can affect pancreatic secretion and organ growth ${ }^{(16-18)}$. An involvement of glucocorticoids has also been demonstrated, although the corticosteroid-dependent pathway was found to be only partially involved in PHAinduced gut maturation, since both enteral and parenteral administrations of PHA increased the plasma corticosteroid concentration similarly, but only the enteral exposure induced maturational changes ${ }^{(14)}$. An alternative mechanism of PHA action could be through the activation of the gut-associated immune system and mediated by release of cytokines and chemokines. In rats it has been demonstrated that growth of

Abbreviations: BW, body weight; GI, gastrointestinal; PHA, phytohaemagglutinin; SI, small intestine.

* Corresponding author: Dr Olena Prykhod'ko, fax +46 4622245 39, email Olena.Prykhodko@cob.lu.se 
the small-intestinal epithelium during weaning was dependent on T-cell activation with an increase in the expression of IL-2 receptors by the gut-associated lymphoid tissue, and proinflammatory cytokines appear to be up-regulated at weaning in the small intestine (SI) of both rats and piglets ${ }^{(19,20)}$.

The aim of the present study was to investigate, in an animal model with a highly immature gut and immune system (the suckling rat model), the dose range in which PHA could provoke precocious GI maturation with minimal acute gut disruption. In addition, the possible involvement of the immune system in this was studied to better understand the mechanisms of PHA action. Thus, the effects on gut and lymphoid organ growth, small-intestinal function and morphology, and the appearance of $\mathrm{CD}^{+}$and $\mathrm{CD}^{+} 9^{+}$cells in the intestinal mucosa were studied after enteral exposure to a single increasing dose of PHA, at $12 \mathrm{~h}$, during the acute phase, and after $3 \mathrm{~d}$, when precocious gut maturation should be developed.

\section{Materials and methods}

\section{Animal model}

The study was performed on rats (Rattus norvegicus) of the Sprague-Dawley stock (Mol:SPRD Han; Taconic M \& B A/S, Ry, Denmark), conventionally bred under a controlled environment $\left(20 \pm 1^{\circ} \mathrm{C} ; 50 \pm 10 \%\right.$ relative humidity; $12 \mathrm{~h}-$ $12 \mathrm{~h}$ light-dark cycle). Each dam with her litter was housed individually and with free access to tap water and a pelleted breeding chow (Rat and Mouse Autoclavable Diet; B\&K Universal AB, Sollentuna, Sweden) dispensed from a lid feed hopper. The birth date of the pups was designated as day 0 and within $2 \mathrm{~d}$ after birth litter sizes were restricted to between ten and twelve pups. The study was approved by the Lund University Ethical Review Committee for Animal Experiments and conducted according to the European Community regulations concerning the protection of experimental animals.

\section{Phytohaemagglutinin preparation}

Red kidney bean (Phaseolus vulgaris) lectin, PHA, was purified by affinity chromatography on Ovomucoid-Sepharose-4B as principally described previously ${ }^{(18,21)}$. In short, red kidney bean glycoproteins were extracted by acetic acid from finely ground kidney beans, concentrated by ultrafiltration and dialysed against $0.05 \mathrm{M}$-2-amino-2-hydroxymethyl-propane-

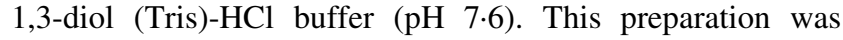
then applied to the affinity column and the unbound material was washed out with $0.05 \mathrm{M}$-Tris- $\mathrm{HCl}$ buffer $(\mathrm{pH} 8)$. Bound PHA was eluted with $0.05 \mathrm{M}$-glycine- $\mathrm{HCl}$ buffer $(\mathrm{pH} 3)$ containing $0 \cdot 25 \mathrm{M}-\mathrm{NaCl}$, dialysed against PBS (in decreasing concentrations from 0.005 to $0.0025 \mathrm{M} ; \mathrm{pH} 7$ ), and finally freeze-dried. Before use, the purified PHA was tested for its activity by haemagglutination.

\section{Experimental procedures}

At age $14 \mathrm{~d}$, the pups were weighed and divided into five treatment groups in a split-litter mode. Two pups per litter (seven litters) were orogastrically fed a single dose of PHA dissolved in saline $(0.9 \% \mathrm{NaCl})$ using a Teflon feeding tube $(0.96 \mathrm{~mm}$ outer diameter; PE50; Becton Dickinson, Sparks, MD, USA) in a volume of $0.01 \mathrm{ml} / \mathrm{g}$ body weight $(\mathrm{BW})$. The PHA doses were: 0 (control), 2, 10, 50 and $250 \mu \mathrm{g} / \mathrm{g} \mathrm{BW}$.

In each litter half of the pups were euthanised at either 12 or $72 \mathrm{~h}$ after the PHA administration. Before dissection the pups were separated from their dam $(\leq 1 \mathrm{~h})$ and anaesthetised by a subcutaneous injection of a mixture of azaperone (Stresnil ${ }^{\circledR}$; Janssen Pharmaceutica, Beerse, Belgium) (30 $\mu \mathrm{g} / \mathrm{g} \mathrm{BW})$ and ketamine $\left(\right.$ Ketalar $^{\circledR}$; Pfizer, New York, NY, USA) $(170 \mu \mathrm{g} / \mathrm{g}$ $\mathrm{BW})$. After opening the abdomen and thorax, the rats were euthanised by bleeding following heart puncture. The entire pancreas was then dissected out and weighed. The SI, from the pylorus to the ileo-caecal junction, was removed and placed on a non-absorbent surface, taking care not to stretch it, and the length was measured. The SI was then divided into a proximal and distal half and the content was flushed out with $1 \mathrm{ml}$ ice-cold saline, then the portions were weighed, immediately frozen and stored at $-70^{\circ} \mathrm{C}$ until analysis. The stomach was dissected, opened and rinsed in ice-cold saline before being weighed. The stomach content was kept on ice for $\mathrm{pH}$ measurements. Finally, the spleen, liver and thymus were dissected out and weighed.

For histology, intestinal samples, $1 \mathrm{~cm}$ long, were taken from the mid part of both the proximal and distal SI portions during the dissection. In addition, for comparison with natural development, histological samples from the same regions of the SI were taken from untreated weaned rats, aged 21 and $28 \mathrm{~d}$, respectively. All intestinal samples were immediately fixed in Bouin's solution for $24 \mathrm{~h}$ and then stored in $70 \%$ ethanol until further processing.

\section{Measurements}

Histology. The fixed intestinal samples were embedded into paraffin, cut laterally into $5 \mu \mathrm{m}$ thick sections and stained with haematoxylin and eosin according to standard procedures. Morphometric parameters, such as villus height and crypt depth, in eight to ten repetitions per sample, were measured in both the proximal and distal SI.

For immunohistochemical analysis of the mucosal immune cells, the histological sections were deparaffinised, blocked for endogenous peroxidase activity in PBS ( $\mathrm{pH} \mathrm{7.2)} \mathrm{containing}$ $1 \% \mathrm{H}_{2} \mathrm{O}_{2}$ and incubated overnight at $+4^{\circ} \mathrm{C}$ with goat polyclonal antibodies against CD19 (diluted 1:100; sc8499; Santa Cruz Biotechnology, Santa Cruz, CA, USA), as a B-cell marker, or rabbit polyclonal anti-CD3e (diluted 1:2000; C7930; Sigma Chemicals, St Louis, MO, USA), as a T-cell marker. The next day, the sections were incubated with secondary antigoat or anti-rabbit horseradish peroxidase-conjugated antibodies (DAKO A/S, Glostrup, Denmark), respectively, for $2 \mathrm{~h}$ at room temperature. To visualise the conjugated peroxidase activity, $\quad 0.05 \%$ 3,3-diaminobenzidine tetrahydrochloride (Sigma Chemicals) was used as the substrate. Thereafter, the sections were counter-stained with haematoxylin, dehydrated and mounted under cover slips. Three independent fields of stained tissue per sample were imaged by using an Olympus PROVIS microscope (objective $\times 20$ ) equipped with an Olympus DP50 camera (Olympus, Tokyo, Japan). In order to investigate the localisation and to quantify, by counting the numbers of $\mathrm{CD}_{1} 9^{+}$and $\mathrm{CD}^{+}$cells $/ \mathrm{mm}^{2}$ of mucosal area of the laterally cut sections from the proximal and distal portions of the SI, the 
ImageJ 1.36 program (National Institutes of Health, Bethesda, MD, USA) was used.

As a positive control to confirm the staining intensity of the primary antibodies, spleen sections were used. To exclude unspecific binding of the secondary horseradish peroxidaseconjugated antibodies, the respective primary antibodies were replaced by $1 \%$ bovine serum albumin and standard procedures were followed.

Intestinal enzymology. The portions of the SI were homogenised in ice-cold $0.9 \% \mathrm{NaCl}(1: 10$, w/v) using a glass homogeniser. The disaccharidase activities, lactase, maltase and sucrase, were measured by incubating the homogenates with the appropriate disaccharide for $1 \mathrm{~h}$ at $37^{\circ} \mathrm{C}$, after which the liberated glucose was measured using a glucose oxidase reagent (Sigma Chemicals), in accordance with the Dahlqvist assay ${ }^{(22)}$. In parallel, the total protein content in the intestinal homogenates was determined by the Lowry method $^{(23)}$, modified for ninety-six-well microplates ${ }^{(24)}$ and using purified bovine serum albumin (Sigma Chemicals) as the standard. The disaccharidase activities were recalculated per mg total protein.

Stomach $\mathrm{pH}$. After adding $1 \mathrm{ml} 0.9 \% \mathrm{NaCl}$ to the stomach contents, mixing and centrifugation at $3000 \mathrm{~g}$ for $15 \mathrm{~min}$, the $\mathrm{pH}$ was measured in the supernatant fraction.

\section{Calculations and statistics}

In order to compensate for individual variations in $\mathrm{BW}$, the organ measurements are presented per $\mathrm{g} \mathrm{BW}$. All data are presented as mean values and standard deviations. Statistical comparisons between all groups at either 12 or $72 \mathrm{~h}$ after PHA treatment were carried out using a one-way ANOVA analysis (SigmaStat 2.0; Jandel Scientific, San Rafael, CA, USA) with all pairwise multiple-comparison procedures (Student-Newman-Keuls method). When the normality or equal variance test failed, Kruskal-Wallis one-way ANOVA on ranks with Dunn's pairwise multiple-comparison method was used. Differences were considered to be significant when $P<0 \cdot 05$.

\section{Results}

Orogastric feeding of the different doses of PHA had no effect on the $\mathrm{BW}$ of the treated rats as compared with that of the time-matched controls (Table 1). Visual observations of the pups indicated that there had been some occurrence of diarrhoea during the first $2-6 \mathrm{~h}$ after treatment with the high PHA doses (50 and $250 \mu \mathrm{g} / \mathrm{g} \mathrm{BW}$ ).

\section{Effect on the gastrointestinal tract}

At $12 \mathrm{~h}$ (acute phase) after PHA administration, little or no effects were seen on the gut organ weights, except after the highest dose of PHA $(250 \mu \mathrm{g} / \mathrm{g} \mathrm{BW})$, which led to a reduction in the liver weight. In addition, this dose had a lowering effect on the $\mathrm{pH}$ of the stomach contents. At $72 \mathrm{~h}$ (late phase) after PHA exposure at the high doses (50 and $250 \mu \mathrm{g} / \mathrm{g} \mathrm{BW})$, both the pancreas and liver weights showed an increase, while the $\mathrm{pH}$ of the stomach contents decreased (Table 1).

During the acute phase, exposure to PHA at 50 and $250 \mu \mathrm{g} / \mathrm{g} \mathrm{BW}$ shortened the small-intestinal villi in both the proximal and distal SI regions (Table 2). Moreover, the crypt depth increased in both regions of the SI after all PHA doses. Later at $72 \mathrm{~h}$, the SI length and the weight of the proximal SI were increased in the groups given PHA at 50 and $250 \mu \mathrm{g} / \mathrm{g} \mathrm{BW}$. In addition, the crypt depth was greater in both the proximal and distal SI of these groups. It was noteworthy that the villus height showed an increase in the distal SI in the groups given PHA at 2 and $10 \mu \mathrm{g} / \mathrm{g} \mathrm{BW}$, while it was decreased at the highest PHA dose in comparison with that of the controls.

At $72 \mathrm{~h}$ post-treatment, the haematoxylin and eosin-stained section from the distal SI of the control group and the groups fed PHA at 2 and $10 \mu \mathrm{g} / \mathrm{g}$ BW showed enterocytes containing supranuclear vacuoles (fetal-type) along the entire villi length (Fig. $1(\mathrm{~A})$ ). In the groups given PHA at 50 and $250 \mu \mathrm{g} / \mathrm{g} \mathrm{BW}$ these fetal-type enterocytes were replaced from the base of the villi by adult-like cells lacking supranuclear vacuoles, reaching approximately three-quarters

Table 1. The acute (at $12 \mathrm{~h}$ ) and late (at $72 \mathrm{~h}$ ) effects after orogastric feeding of increasing doses of phytohaemagglutinin (PHA) to suckling rats, aged $14 \mathrm{~d}$, on body weight $(\mathrm{g})$, stomach $\mathrm{pH}$, and gut and lymphoid organ weights ( $\mathrm{mg} / \mathrm{g}$ body weight)

(Mean values and standard deviations for five to eight determinations)

\begin{tabular}{|c|c|c|c|c|c|c|c|c|c|c|c|c|c|c|}
\hline \multirow[b]{2}{*}{ PHA dose ( $\mu \mathrm{g} / \mathrm{g}$ body weight) } & \multicolumn{2}{|c|}{ Body weight } & \multicolumn{2}{|c|}{$\begin{array}{c}\text { Stomach } \\
\text { weight }\end{array}$} & \multicolumn{2}{|c|}{ Stomach $\mathrm{pH}$} & \multicolumn{2}{|c|}{$\begin{array}{c}\text { Pancreas } \\
\text { weight }\end{array}$} & \multicolumn{2}{|c|}{ Liver weight } & \multicolumn{2}{|c|}{$\begin{array}{l}\text { Thymus } \\
\text { weight }\end{array}$} & \multicolumn{2}{|c|}{$\begin{array}{l}\text { Spleen } \\
\text { weight }\end{array}$} \\
\hline & Mean & SD & Mean & $\mathrm{SD}$ & Mean & SD & Mean & SD & Mean & SD & Mean & SD & Mean & SD \\
\hline \multicolumn{15}{|l|}{$12 \mathrm{~h}$ after treatment } \\
\hline 0 & 33.6 & 3 & $6 \cdot 3$ & 0.5 & $5 \cdot 7^{\mathrm{a}, \mathrm{b}}$ & 0.2 & 3.0 & 0.5 & $34.7^{\mathrm{a}}$ & 1.7 & 5.4 & 0.8 & $4 \cdot 9^{\mathrm{a}}$ & 0.5 \\
\hline 2 & 34.0 & 3 & $6 \cdot 2$ & 0.7 & $5 \cdot 6^{a, b}$ & 0.2 & $2 \cdot 8$ & 0.4 & $33 \cdot 2^{a, b}$ & $1 \cdot 1$ & $5 \cdot 1$ & 0.5 & $5 \cdot 0^{\mathrm{a}}$ & 0.5 \\
\hline 10 & $32 \cdot 8$ & 4 & $6 \cdot 4$ & 0.6 & $5 \cdot 6^{\mathrm{a}, \mathrm{b}}$ & 0.2 & $2 \cdot 8$ & 0.3 & $34 \cdot 1^{\mathrm{a}}$ & 1.5 & $5 \cdot 0$ & 1.0 & $4.7^{\mathrm{a}}$ & 0.4 \\
\hline 50 & $34 \cdot 2$ & 3 & $6 \cdot 3$ & 0.7 & $5 \cdot 2^{\mathrm{a}, \mathrm{b}}$ & 0.6 & $2 \cdot 6$ & 0.1 & $32 \cdot 4^{\mathrm{a}, \mathrm{b}}$ & $2 \cdot 3$ & $5 \cdot 3$ & 0.7 & $4.7^{\mathrm{a}}$ & 0.8 \\
\hline 250 & 33.9 & 2 & 6.4 & 0.4 & $4.4^{\mathrm{b}}$ & 0.4 & $2 \cdot 7$ & 0.3 & $30 \cdot 4^{\mathrm{b}}$ & $1 \cdot 1$ & $5 \cdot 1$ & 0.3 & $3.8^{\mathrm{b}}$ & 0.6 \\
\hline \multicolumn{15}{|l|}{$72 \mathrm{~h}$ after treatment } \\
\hline 0 & 42.5 & 4 & $7 \cdot 3$ & 0.9 & $5 \cdot 1^{x}$ & 0.1 & $3 \cdot 5^{\mathrm{x}}$ & 0.5 & $40 \cdot 5^{\mathrm{x}}$ & 3.0 & $5 \cdot 5^{\mathrm{x}}$ & 0.7 & $4 \cdot 8^{x, y}$ & 0.7 \\
\hline 2 & $40 \cdot 7$ & 3 & $6 \cdot 7$ & 0.3 & $5 \cdot 2^{x, y}$ & 0.3 & $3 \cdot 5^{x}$ & 0.5 & $40 \cdot 4^{x}$ & 1.6 & $5 \cdot 2^{x}$ & 0.5 & $4 \cdot 6^{x, y}$ & 0.3 \\
\hline 10 & $42 \cdot 4$ & 5 & $6 \cdot 8$ & 0.8 & $5 \cdot 2^{x}$ & 0.2 & $3 \cdot 4^{x}$ & 0.2 & $40 \cdot 0^{x}$ & $2 \cdot 4$ & $5 \cdot 5^{\mathrm{x}}$ & 0.9 & $5 \cdot 0^{x}$ & 0.8 \\
\hline 50 & 41.6 & 1 & $7 \cdot 6$ & 0.1 & $4 \cdot 9^{y, z}$ & 0.2 & $4 \cdot 0^{y}$ & 0.3 & $42 \cdot 0^{x}$ & 4.4 & $4 \cdot 8^{x}$ & 0.5 & $4 \cdot 8^{x, y}$ & 0.6 \\
\hline 250 & 39.4 & 4 & 7.9 & 0.7 & $4 \cdot 7^{z}$ & 0.2 & $4 \cdot 3^{y}$ & 0.3 & $47 \cdot 0^{y}$ & $4 \cdot 1$ & $3 \cdot 5^{y}$ & 0.6 & $3 \cdot 9^{y}$ & 0.5 \\
\hline
\end{tabular}

${ }^{a, b}$ Mean values within a column for $12 \mathrm{~h}$ after treatment with unlike superscript letters were significantly different $(P<0.05)$.

$\mathrm{x}, \mathrm{y}, \mathrm{z}$ Mean values within a column for $72 \mathrm{~h}$ after treatment with unlike superscript letters were significantly different $(P<0.05)$. 
Table 2. The acute (at $12 \mathrm{~h}$ ) and late (at $72 \mathrm{~h}$ ) effects after orogastric feeding of increasing doses of phytohaemagglutinin (PHA) to suckling rats, aged $14 \mathrm{~d}$, on the small-intestinal length ( $\mathrm{cm} / \mathrm{g}$ body weight), proximal and distal weights ( $\mathrm{mg} / \mathrm{g}$ body weight), villi height $(\mu \mathrm{m})$ and crypt depth $(\mu \mathrm{m})$ (Mean values and standard deviations for five to eight determinations)

\begin{tabular}{|c|c|c|c|c|c|c|c|c|c|c|c|c|c|c|}
\hline \multirow[b]{3}{*}{ PHA dose ( $\mu \mathrm{g} / \mathrm{g}$ body weight) } & & & \multicolumn{6}{|c|}{ Proximal small intestine } & \multicolumn{6}{|c|}{ Distal small intestine } \\
\hline & \multicolumn{2}{|c|}{$\begin{array}{l}\text { Small-intesti- } \\
\text { nal length }\end{array}$} & \multicolumn{2}{|c|}{ Weight } & \multicolumn{2}{|c|}{ Villi height } & \multicolumn{2}{|c|}{ Crypt depth } & \multicolumn{2}{|c|}{ Weight } & \multicolumn{2}{|c|}{ Villi height } & \multicolumn{2}{|c|}{ Crypt depth } \\
\hline & Mean & SD & Mean & SD & Mean & SD & Mean & SD & Mean & $\mathrm{SD}$ & Mean & SD & Mean & SD \\
\hline \multicolumn{15}{|l|}{$12 \mathrm{~h}$ after treatment } \\
\hline 0 & 1.5 & 0.1 & $16 \cdot 3$ & 1 & $461^{a}$ & 23 & $53^{\mathrm{a}}$ & 4 & $15 \cdot 4$ & 2 & $509^{a}$ & 42 & $50^{\mathrm{a}}$ & 4 \\
\hline 2 & 1.5 & 0.1 & $16 \cdot 1$ & 1 & $491^{a}$ & 51 & $64^{\mathrm{b}}$ & 5 & 14.7 & 1 & $501^{\mathrm{a}, \mathrm{b}}$ & 35 & $55^{\mathrm{b}}$ & 2 \\
\hline 10 & 1.6 & 0.2 & $16 \cdot 8$ & 1 & $480^{\mathrm{a}}$ & 37 & $60^{\mathrm{b}}$ & 3 & $15 \cdot 2$ & 1 & $493^{\mathrm{a}}$ & 46 & $57^{\mathrm{b}, \mathrm{c}}$ & 5 \\
\hline 50 & 1.5 & 0.1 & $15 \cdot 7$ & 3 & $346^{\mathrm{b}}$ & 36 & $63^{\mathrm{b}}$ & 6 & $15 \cdot 8$ & 1 & $429^{b, c}$ & 70 & $61^{\mathrm{c}}$ & 2 \\
\hline 250 & 1.5 & 0.2 & 13.7 & 1 & $288^{\mathrm{c}}$ & 53 & $63^{\mathrm{b}}$ & 2 & 14.3 & 2 & $410^{C}$ & 45 & $58^{\mathrm{b}, \mathrm{c}}$ & 3 \\
\hline \multicolumn{15}{|l|}{$72 \mathrm{~h}$ after treatment } \\
\hline 0 & $1 \cdot 3^{x}$ & 0.1 & $20 \cdot 2^{x}$ & 2 & 478 & 35 & $62^{x}$ & 3 & $19 \cdot 3$ & 2 & $501^{x}$ & 53 & $63^{x}$ & 5 \\
\hline 2 & $1.4^{x}$ & 0.1 & $19 \cdot 9^{x}$ & 2 & 530 & 36 & $71^{x, y}$ & 7 & 19.5 & 2 & $569^{y}$ & 27 & $63^{x}$ & 2 \\
\hline 10 & $1 \cdot 3^{x}$ & 0.1 & $20 \cdot 9^{x}$ & 2 & 495 & 32 & $66^{x}$ & 3 & 19.7 & 2 & $569^{y}$ & 51 & $65^{x}$ & 4 \\
\hline 50 & $1 \cdot 4^{\mathrm{x}}$ & 0.1 & $24 \cdot 4^{y}$ & 3 & 513 & 39 & $76^{y}$ & 8 & $20 \cdot 1$ & 3 & $498^{x}$ & 34 & $71^{x, y}$ & 2 \\
\hline 250 & $1 \cdot 6^{y}$ & 0.2 & $31 \cdot 5^{z}$ & 4 & 521 & 35 & $88^{z}$ & 9 & 22.9 & 2 & $374^{z}$ & 37 & $90^{y}$ & 14 \\
\hline
\end{tabular}

a,b,c Mean values within a column for $12 \mathrm{~h}$ after treatment with unlike superscript letters were significantly different $(P<0.05)$.

${ }^{x, y, z}$ Mean values within a column for $72 \mathrm{~h}$ after treatment with unlike superscript letters were significantly different $(P<0.05)$.

of the length of the villi in the group fed PHA at $50 \mu \mathrm{g} / \mathrm{g} \mathrm{BW}$, and almost the entire length of the villi in the group given PHA at $250 \mu \mathrm{g} / \mathrm{g}$ BW (Figs. 1 (B) and (C)).

At $12 \mathrm{~h}$ after PHA treatment in the groups fed PHA at 50 and $250 \mu \mathrm{g} / \mathrm{g} \mathrm{BW}$, the lactase and maltase activities were decreased along the entire SI, as compared with their timematched groups (Fig. 2). In general, the sucrase activity was very low at this age. At $72 \mathrm{~h}$ post-treatment, the lactase activity was restored to the control levels except for that in the treatment group given PHA at $250 \mu \mathrm{g} / \mathrm{g} \mathrm{BW}$, where it showed a decrease in both SI regions. At the same time, in the groups fed PHA at 50 and $250 \mu \mathrm{g} / \mathrm{g} \mathrm{BW}$, there was a noticeable increase in the maltase and sucrase activities in both regions of the SI.

\section{Effect on lymphoid organs and intestinal immune cells}

Initially, at $12 \mathrm{~h}$ after treatment, PHA had no significant effect on the thymus weight, but at $72 \mathrm{~h}$ the thymus weight

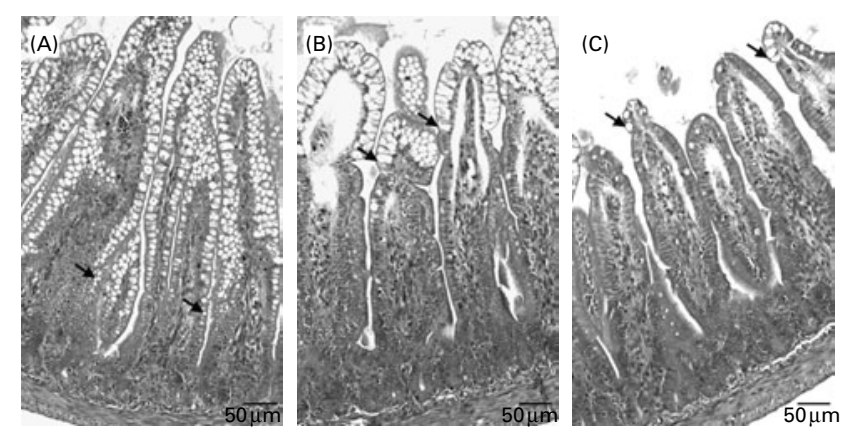

Fig. 1. Photomicrographs of the haematoxylin and eosin-stained distal small intestine at $72 \mathrm{~h}$ after orogastric feeding of phytohaemagglutinin (PHA) at 0 (control; A), 50 (B) and 250 (C) $\mu \mathrm{g} / \mathrm{g}$ body weight (BW), respectively, to suckling rats aged $14 \mathrm{~d}$. The villi show enterocytes containing supranuclear vacuoles (fetal type) $(\rightarrow)$ all along the villi in the controls $(A)$, while in the PHAtreated rats these cells are replaced by enterocytes lacking the supranuclear vacuoles (adult type) up to the upper half of the villi in the group fed PHA at $50 \mu \mathrm{g} / \mathrm{g} \mathrm{BW}(\mathrm{B})$ and almost to the top in the group fed PHA at $250 \mu \mathrm{g} / \mathrm{g} \mathrm{BW}(\mathrm{C})$. showed a reduction in the group given PHA at $250 \mu \mathrm{g} / \mathrm{g}$ BW (Table 1). Moreover, in the $250 \mu \mathrm{g} / \mathrm{g}$ BW treatment group, the spleen weight was decreased at both 12 and $72 \mathrm{~h}$ post-treatment, in comparison with that of their time-matched groups.

The immunohistological studies showed that there was an age-dependent increase in the number of both $\mathrm{CD} 19^{+}$ and $\mathrm{CD}^{+}$cells in the intestinal mucosa of normal, 21- and 28-d-old weaned rats as compared with that in the younger suckling, 14.5- or 17-d-old control rats (Fig. 3). After enteral administration, in the groups treated with PHA at 50 and $250 \mu \mathrm{g} / \mathrm{g} \mathrm{BW}$, an increase in the number of both $\mathrm{CD} 19^{+}$ and $\mathrm{CD}^{+}$cells in the intestinal mucosa was observed at both 12 and $72 \mathrm{~h}$ post-treatment in comparison with the age-matched groups. In the controls and low PHA dose exposure groups, the $\mathrm{CD}_{1} 9^{+}$and $\mathrm{CD}^{+}$cells were located in the crypt region as well as in the lamina propria in the upper part of villi in the proximal SI, while in the distal part of the SI they were mainly found in the crypt and lower villi zone. In contrast, in the groups given PHA at 50 and $250 \mu \mathrm{g} / \mathrm{g} \mathrm{BW}$, these were found along the entire villi (Fig. 4).

\section{Discussion}

The present study showed that a single orogastric administration of PHA to suckling rats aged $14 \mathrm{~d}$ resulted in doserelated effects on the GI tract. The low doses of PHA did not result in any apparent disturbances of the GI tract during the acute phase, nor did it provoke gut precocious maturation later on, at $3 \mathrm{~d}$; however, it did induce intestinal hyperplasia. Treatment with higher doses of PHA initially caused a mucosal disarrangement that temporarily affected the gut function coupled to growth stimulation and precocious maturation after $3 \mathrm{~d}$. These later effects on the gut, provoked by the higher PHA doses, were correlated with an increase in the density of T- $\left(\mathrm{CD}^{+}\right)$and B- $\left(\mathrm{CD} 19^{+}\right)$lymphocytes in the small-intestinal mucosa, possibly indicating an 
(A)

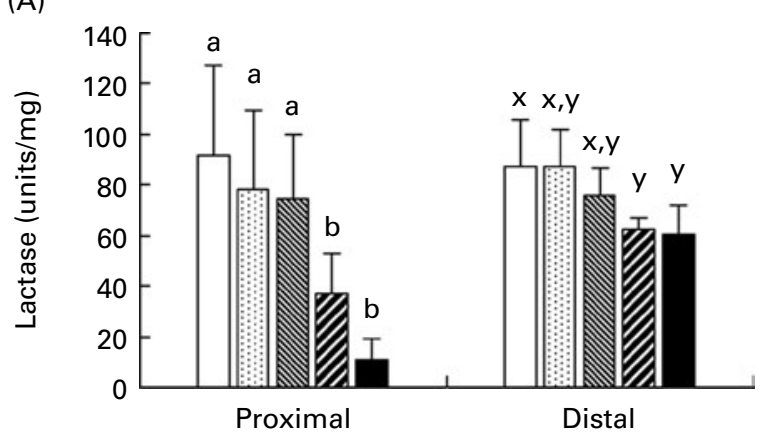

(C)

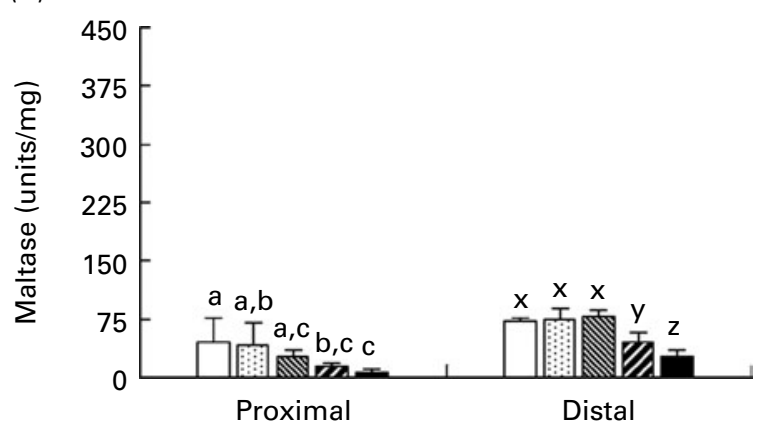

(E)

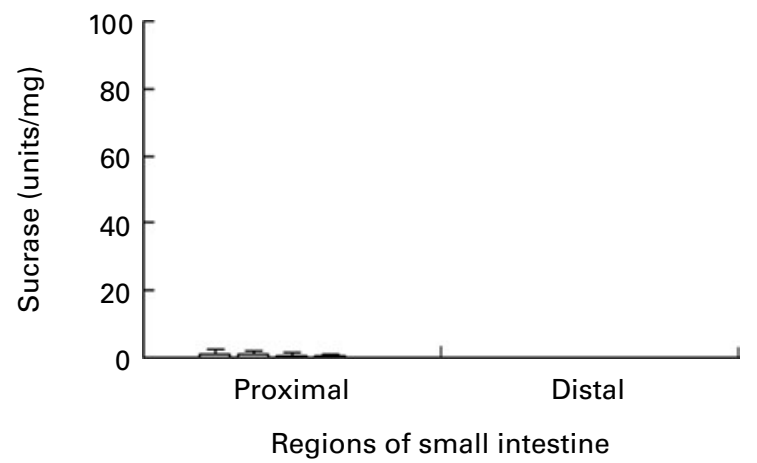

(B)

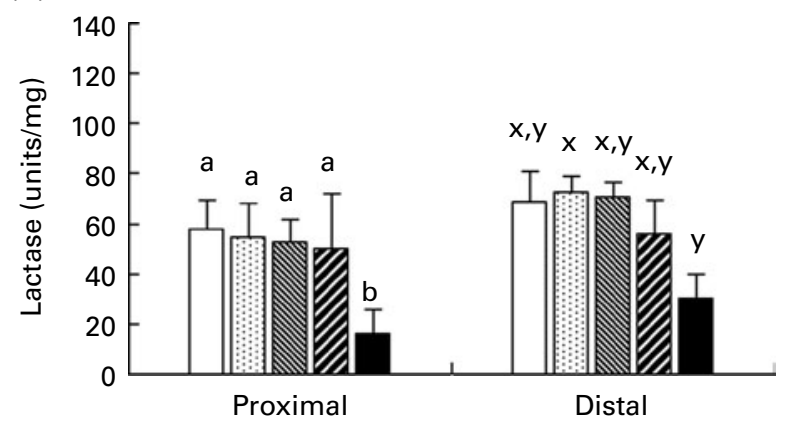

(D)

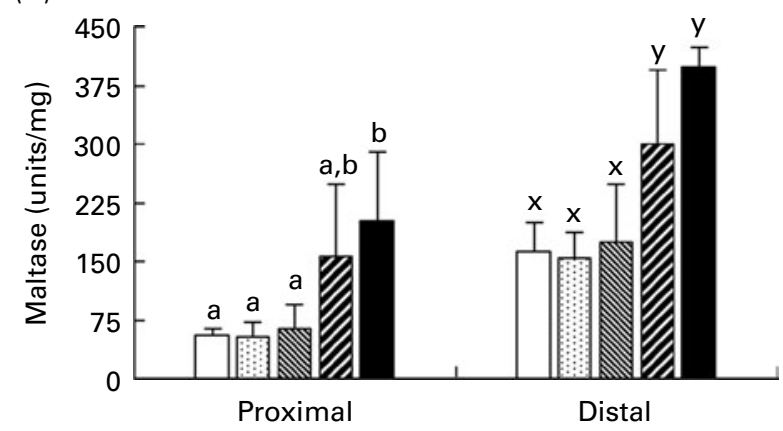

(F)

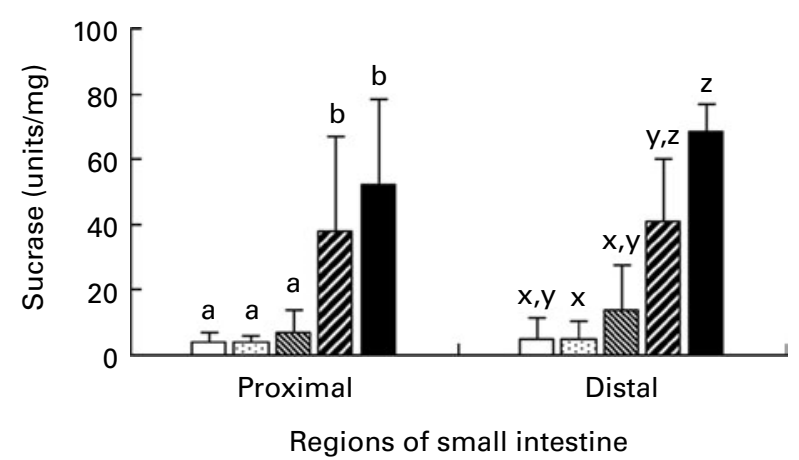

Fig. 2. Effect of exposure to increasing doses of phytohaemagglutinin at $0(\square), 2(\square), 10(\mathbb{Q}), 50(\mathbb{Z})$ and $250(\square) \mu g / g$ body weight, respectively, on mucosal disaccharidase activities (units/mg protein) in the proximal and distal small intestine at $12 \mathrm{~h}(\mathrm{~A}, \mathrm{C}, \mathrm{E})$ and $72 \mathrm{~h}(\mathrm{~B}, \mathrm{D}, \mathrm{F})$ after orogastric feeding to suckling rats aged $14 \mathrm{~d}(n 5-6)$. Values are means, with standard deviations represented by vertical bars. The results show a dose-related decrease in lactase and maltase activities at $12 \mathrm{~h}$, but an increase in maltase and sucrase activities at $72 \mathrm{~h}$, in both parts of the small intestine. ${ }^{\mathrm{a}, \mathrm{b}, \mathrm{c}}$ Mean values for $12 \mathrm{~h}$ after treatment with unlike letters were significantly different $(P<0 \cdot 05) .{ }^{x, y, z}$ Mean values for $72 \mathrm{~h}$ after treatment with unlike letters were significantly different $(P<0 \cdot 05)$.

involvement of the immune system in the PHA-induced precocious maturation of the gut.

\section{The acute effects of phytohaemagglutinin treatment}

The results obtained after exposure to the high PHA doses confirmed those of a previous study showing a temporary disturbance of the rat's intestinal mucosa after exposure, manifested by reduction in the weight of the SI, shortening of the villi and a decrease in the intestinal brush-border lactase and maltase activities ${ }^{(13)}$. Besides the shortening of the intestinal villi there was possibly a cell loss and also probably a disarrangement of the microvilli of the remanding enterocytes ${ }^{(25)}$, explaining the decrease in the disaccharidase activities.

The acute effects of PHA at $12 \mathrm{~h}$ appeared after direct binding of PHA to the gut epithelium ${ }^{(13)}$. The intestinal crypt hyperplasia, which was observed to be independent of the PHA dose, could be stimulated via a direct PHA signal, for instance, activating mitogen-activated protein kinase in the enterocytes. The mitogen-activated protein kinase cascade, required for cell differentiation and growth, has been shown to be activated in both human and rodent intestinal cell-lines after exposure to different doses of $\mathrm{PHA}^{(26)}$.

In the stomach, exposure to PHA might affect the parietal cells also through direct binding ${ }^{(27)}$, resulting in increased $\mathrm{HCl}$ secretion and subsequent decrease in luminal $\mathrm{pH}$ as observed in the stomach contents. In a corresponding manner, PHA could also stimulate gastrin-secreting and/or enterochromaffin-like cells, affecting the $\mathrm{HCl}$ secretion in the stomach. The stomach contents with decreased $\mathrm{pH}$ passing into the duodenum could then stimulate the release of secretin and thereby stimulate pancreatic exocrine function. Moreover, 
(A)

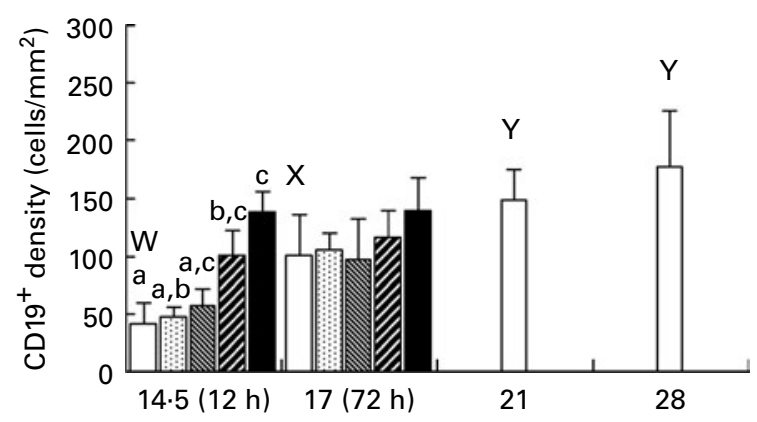

(C)

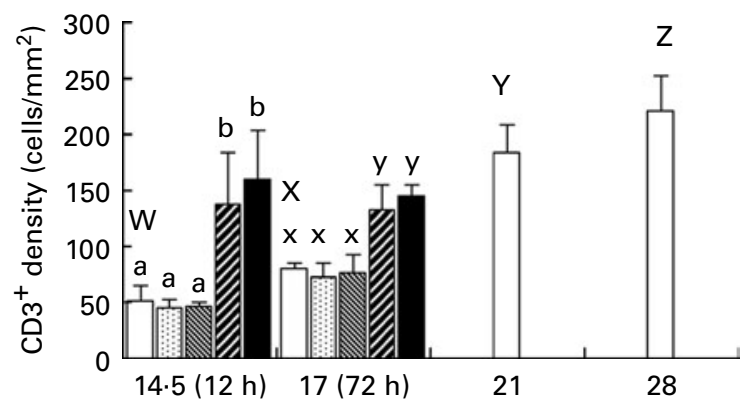

Age (d) and time after PHA treatment
(B)

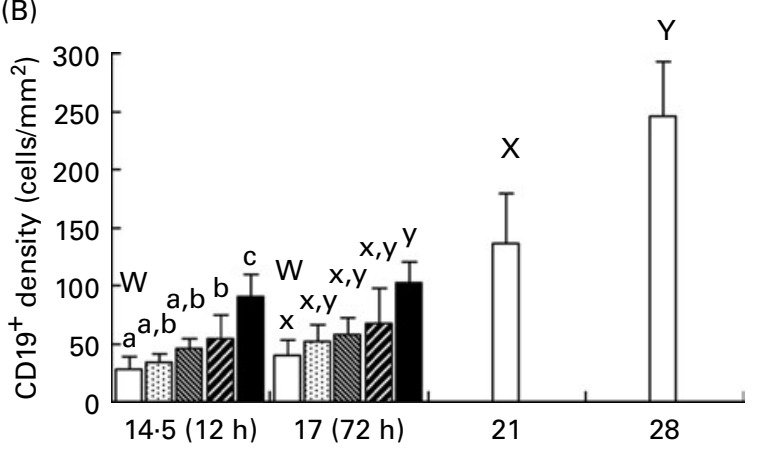

(D)

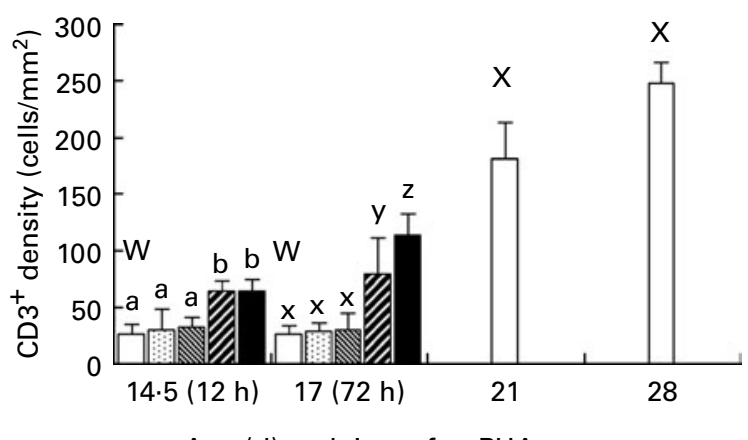

Age (d) and time after PHA treatment

Fig. 3. Effect of exposure to increasing doses of phytohaemagglutinin (PHA) at $0(\square), 2(\square), 10(\mathbb{Q}), 50(\mathbb{Z})$ and $250(\square) \mu \mathrm{g} / \mathrm{g}$ body weight, respectively, on mucosal $\mathrm{CD}_{19}{ }^{+}(\mathrm{A}, \mathrm{B})$ and $\mathrm{CD}^{+}(\mathrm{C}, \mathrm{D})$ cells in the proximal (A, C) and distal (B, D) small intestine at 12 (age 14.5 d) and 72 (age $\left.17 \mathrm{~d}\right) \mathrm{h}$ after orogastric feeding, in comparison with that of untreated weaned rats aged 21 and $28 \mathrm{~d}(\square)$, as evaluated by immunohistochemistry. Values are means $(n 5)$, with standard deviations represented by vertical bars. The results show increased densities of both $\mathrm{CD}_{19}{ }^{+}$(B-lymphocyte) and $\mathrm{CD}^{+}$(T-lymphocyte) cells at $12 \mathrm{~h}$ after treatment in both parts of the small intestine for the two highest PHA doses, which parallel results of weaned rats showing an increase in numbers of B-and T- mucosal immune cells at weaning. ${ }^{\mathrm{a}, \mathrm{b}, \mathrm{c}}$ Mean values for $12 \mathrm{~h}$ after treatment with unlike letters were significantly different $(P<0 \cdot 05)$. ${ }^{\mathrm{x}, \mathrm{y}, \mathrm{z}}$ Mean values for $72 \mathrm{~h}$ after treatment with unlike letters were significantly different $(P<0.05)$. ${ }^{\mathrm{W}, X, Y, Z}$ Mean values for untreated weaned rats and younger controls with unlike letters were significantly different $(P<0.05)$.

direct PHA-binding to the intestinal cells, including the enteroendocrine cells, could result in a release of GI hormones, stimulating the pancreas via a cholecystokinin-dependent pathway ${ }^{(16-18)}$.

Upon exposure to PHA, especially at high doses, it was observed that the lectin affected the lymphoid tissue, and the reduction in spleen weight indicated that it could be a mobilisation of immune cells from the spleen to, possibly, the intestine. The increased density of T- and B- marked cells in the intestinal mucosa by $12 \mathrm{~h}$ after treatment demonstrates that there had been a rapid expansion of mucosal immune cells, well before any maturational changes in the GI tract could be observed. These results indicate that the acute effects of PHA on the gut might be linked to the activation of the immune system.

\section{The late effects of phytohaemagglutinin treatment}

At $3 \mathrm{~d}$ after administration, when PHA-binding in the GI tract had subsided or disappeared ${ }^{(13,28)}$, a prominent dose-dependent effect was observed with respect to growth and precocious functional development of the GI tract in the suckling rats. While the low doses of PHA did not lead to any gut maturation, they still stimulated intestinal growth, as shown by villus hyperplasia, which agreed with a previous study that showed increased crypt cell proliferation after a single orogastric feeding of PHA ${ }^{(13)}$. Thus, all PHA doses appeared to have a proliferative effect, while only high PHA doses could provoke functional maturation, here shown by a change in the intestinal enterocyte features, i.e. from a fetal phenotype with lactase as a predominant disaccharidase and with enterocytes containing large supranuclear vacuoles, to an adult phenotype with higher maltase and sucrase activities and lacking the supranuclear vacuoles in the distal region of the $\mathrm{SI}^{(1-4)}$. The decreased $\mathrm{pH}$ in the stomach contents and stimulation of the accessory glands of the GI tract, for example, pancreas and liver growth, observed after highdose PHA treatment also agreed with functional maturation ${ }^{(13,14)}$. The liver-weight increase could be explained, possibly, by an activation and synthesis of acute-phase proteins, for example, haptoglobin or C-reactive protein, which indicate activation of the immune system ${ }^{(29)}$.

Also, the lymphoid organs, both the thymus and spleen, were affected by the higher doses of $\mathrm{PHA}^{(30,31)}$. The reduction in thymus weight could be explained by a possible mobilisation and migration of T-lymphocytes from this organ, while the decreased spleen weight observed after treatment with PHA at $250 \mu \mathrm{g} / \mathrm{g}$ BW might be due to either mobilisation of immune cells from this organ or to a redistribution of blood cells due to the treatment.

In addition, the increased numbers of T- and B- markerexpressing cells in small-intestinal mucosa indicate an 

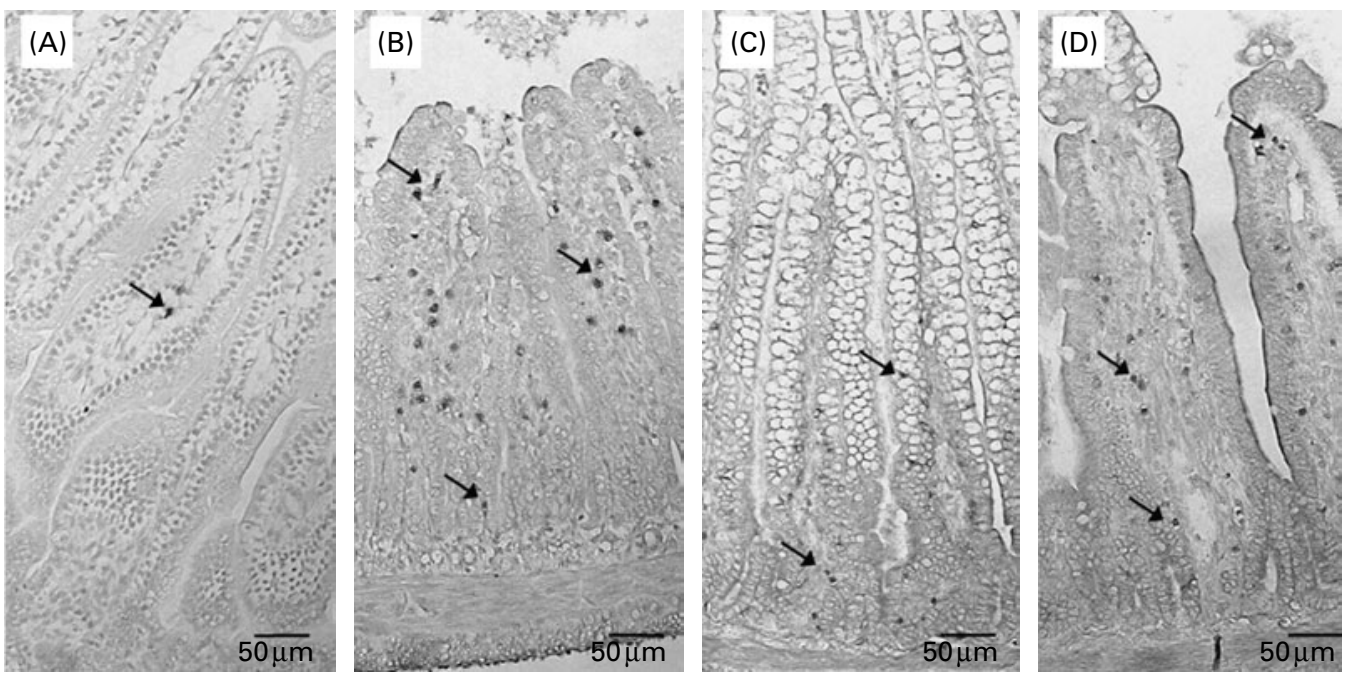

Fig. 4. Photomicrographs of the small intestine stained by immunohistochemistry, showing expression and localisation of $C D 19^{+}$cells in the proximal part at $12 \mathrm{~h}(\mathrm{~A}, \mathrm{~B})$ and $\mathrm{CD}^{+}$cells in the distal part at $72 \mathrm{~h}$ after enteral administration $(\mathrm{C}, \mathrm{D})$ of saline $(\mathrm{A}, \mathrm{C})$ or phytohaemagglutinin $(\mathrm{PHA})$ at $250 \mu \mathrm{g} / \mathrm{g}$ body weight $(\mathrm{B}, \mathrm{D})$ to suckling rats aged $14 \mathrm{~d}$. After $12 \mathrm{~h}$ in the proximal small intestine, the control pups (A) showed a few CD19+ cells (B-lymphocytes) in the lamina propria, while in the PHA-fed pups (B) $\mathrm{CD}_{19^{+}}$cells appeared along the whole villi $(\rightarrow)$. After $72 \mathrm{~h}$ in the distal small intestine, control pups (C) showed CD3 ${ }^{+}$cells $(\mathrm{T}$-lymphocytes) mostly in the crypt region and the lower part of the villi, while in the PHA-treated pups (D) they were found from the crypt region in the lamina propria up to the top of the villi ( $\rightarrow$ ).

association between the activation of the immune system and the induced precocious maturation of the GI tract after PHA exposure. These findings paralleled the present results obtained from the untreated rats, which showed an increase in the numbers of intestinal mucosal T- and B-cells during natural weaning, and agreed with other studies demonstrating an involvement of the immune system in gut growth and development ${ }^{(9,10,32)}$. Studies in vitro have shown an involvement of activated T-cells in epithelial proliferation and crypt hyperplasia in human fetal SI cells ${ }^{(33)}$. Moreover, by using cyclosporine A as an immunosuppressant in vivo, it has been shown that a reduction in T-cell activity led to a decrease in intestinal growth, including crypt proliferation and the villus area, and signs of delayed gut maturation in weaning rats ${ }^{(32)}$. However, in hypothymic nude rats, the activation of T-cells and intestinal development during weaning is similar to that of normal euthymic rats ${ }^{(34)}$, indicating the importance of extrathymic intestinal T-cell development, especially for intra-epithelial lymphocytes ${ }^{(35,36)}$. The role of B-cells in rat intestinal maturation is unknown; nevertheless, their organogenic function has been shown with respect to the development of Peyer's patches and M-cells ${ }^{(37)}$.

In the present study, the observed rapid expansion of immune cells in the small-intestinal mucosa, before later gut development, indicated that PHA-induced gut maturation may be influenced by immune factors. It could be speculated that PHA bound to the immature small-intestinal epithelium could affect the secretion of growth factors, for example, transforming growth factor- $\alpha$ and/or cytokines, for example, IL-2, IL- $1 \beta$ and IL- 6 and TNF- $\alpha$, that stimulate the immune cell recruitment and activation, which in turn could be involved in stimulating GI tract growth and especially development ${ }^{(9,19,20,38)}$. In fact, the involvement of cytokines has been demonstrated in precocious spermin-induced maturation of the SI in suckling rats ${ }^{(39,40)}$. However, the possible role of the immune system in PHA-induced gut maturation needs to be further studied.

In conclusion, enteral exposure to single doses of PHA had a dose-related effect on the GI tract in suckling rats. Low dosages of PHA acted as a stimulator of hyperplasic intestinal epithelial growth, while higher doses of PHA also caused transient epithelial disturbances and an expansion of immune cells in the intestinal mucosa followed by maturational changes of the GI tract. These findings contribute to increase the understanding of the mechanisms involved in diet-induced precocious gut maturation and suggest a possible role of the immune system in this process. The results obtained on suckling rats, here used as a model for mammals born with an immature gut, also show that dietary manipulation with lectins or other substances causing a mild insult in the gut might be used as a treatment to induce gut maturation with improved function.

\section{Acknowledgements}

The authors would like to thank Mrs Inger Mattsson for her help with the analyses and are thankful for the financial support from the Swedish Research Council for Environment, Agricultural Sciences and Spatial Planning (FORMAS) and the Royal Physiographic Society of Lund. O. P. planned the study, performed all experiments and part of the analyses and wrote the paper. O. F. assisted in performing the experiments, part of the analyses and in writing the paper. A. L. and S. P. planned the study and assisted in writing the paper. B. W. planned the study, assisted in performing the experiments and in writing the paper. There are no conflicts of interest.

\section{References}

1. Baintner K (2002) Vacuolization in the young. In Biology of the Intestine in Growing Animals, vol. 1, pp. 55-110 [R Zabielski, PS Gregory and B Weström, editors]. Amsterdam: Elsevier Science B. V.

2. Henning SJ (1981) Postnatal development: coordination of feeding, digestion, and metabolism. Am J Physiol 241, G199-G214.

3. Pacha J (2000) Development of intestinal transport function in mammals. Physiol Rev 80, 1633-1667. 
4. Walthall K, Cappon GD, Hurtt ME \& Zoetis T (2005) Postnatal development of the gastrointestinal system: a species comparison. Birth Defects Res 74B, 132-156.

5. Holsapple MP, West LJ \& Landreth KS (2003) Species comparison of anatomical and functional immune system development. Birth Defects Res 68, 321-334.

6. McCracken VJ \& Robin GL (2001) The gastrointestinal ecosystem: a precarious alliance among epithelium, immunity and microbiota. Cell Microbiol 3, 1-11.

7. Perez-Cano FJ, Castellote C, Gonzalez-Castro AM, Pelegri C, Castell M \& Franch A (2005) Developmental changes in intraepithelial T lymphocytes and NK cells in the small intestine of neonatal rats. Pediatr Res 58, 885-891.

8. Cummins AG \& Thompson FM (2002) Effect of breast milk and weaning on epithelial growth of the small intestine in humans. Gut 51, 748-754.

9. Masjedi M, Tivey DR, Thompson FM \& Cummins AG (1999) Activation of the gut-associated lymphoid tissue with expression of interleukin-2 receptors that peaks during weaning in the rat. J Pediatr Gastroenterol Nutr 29, 556-562.

10. Thompson FM, Mayrhofer G \& Cummins AG (1996) Dependence of epithelial growth of the small intestine on T-cell activation during weaning in the rat. Gastroenterology 111, 37-44.

11. Radberg K, Biernat M, Linderoth A, Zabielski R, Pierzynowski SG \& Westrom BR (2001) Enteral exposure to crude red kidney bean lectin induces maturation of the gut in suckling pigs. J Anim Sci 79, 2669-2678.

12. Linderoth A, Biernat M, Prykhodko O, Kornilovska I, Pusztai A, Pierzynowski SG \& Bjorn WR (2005) Induced growth and maturation of the gastrointestinal tract after Phaseolus vulgaris lectin exposure in suckling rats. J Pediatr Gastroenterol Nutr 41, 195-203.

13. Linderoth A, Prykhod'ko O, Ahren B, Fak F, Pierzynowski SG \& Westrom BR (2006) Binding and the effect of the red kidney bean lectin, phytohaemagglutinin, in the gastrointestinal tract of suckling rats. Br J Nutr 95, 105-115.

14. Linderoth A, Prykhod'ko O, Pierzynowski SG \& Weström BR (2006) Enterally but not parenterally administered Phaseolus vulgaris lectin induces growth and precocious maturation of the gut in suckling rats. Biol Neonate 89, 60-68.

15. Thomsson A, Rantzer D, Westrom BR, Pierzynowski SG \& Svendsen J (2007) Effects of crude red kidney bean lectin (phytohemagglutinin) exposure on performance, health, feeding behavior, and gut maturation of pigs at weaning. J Anim Sci 85, 477-485.

16. Grant G, Alonso R, Edwards JE \& Murray S (2000) Dietary soya beans and kidney beans stimulate secretion of cholecystokinin and pancreatic digestive enzymes in 400-day-old HoodedLister rats but only soya beans induce growth of the pancreas. Pancreas 20, 305-312

17. Grant G, Edwards JE, Ewan EC, Murray S, Atkinson T, Farningham DA \& Pusztai A (1999) Secretion of pancreatic digestive enzymes induced in rats by first-time oral exposure to kidney bean E2L2 lectin is mediated only in part by cholecystokinin (CCK). Pancreas 19, 382-389.

18. Herzig KH, Bardocz S, Grant G, Nustede R, Folsch UR \& Pusztai A (1997) Red kidney bean lectin is a potent cholecystokinin releasing stimulus in the rat inducing pancreatic growth Gut 41, 333-338.

19. Pie S, Lalles JP, Blazy F, Laffitte J, Seve B \& Oswald IP (2004) Weaning is associated with an upregulation of expression of inflammatory cytokines in the intestine of piglets. $J$ Nutr 134, 641-647.

20. Schaeffer C, Diab-Assef M, Plateroti M, Laurent-Huck F, Reimund JM, Kedinger M \& Foltzer-Jourdainne C (2000) Cytokine gene expression during postnatal small intestinal development: regulation by glucocorticoids. Gut 47, 192-199.
21. Pusztai A \& Watt WB (1974) Isolectins of Phaseolus vulgaris. A comprehensive study of fractionation. Biochim Biophys Acta 365, $57-71$

22. Dahlqvist A (1984) Assay of intestinal disaccharidases. Scand J Clin Lab Invest 44, 169-172.

23. Lowry OH, Rosebrough NJ, Farr AL \& Randall RJ (1951) Protein measurement with the Folin phenol reagent. $J$ Biol Chem 193, 265-275.

24. Pierzynowski SG, Westrom BR, Svendsen J \& Karlsson BW (1990) Development of exocrine pancreas function in chronically cannulated pigs during 1-13 weeks of postnatal life. J Pediatr Gastroenterol Nutr 10, 206-212.

25. Hagen SJ, Trier JS \& Dambrauskas R (1994) Exposure of the rat small intestine to raw kidney beans results in reorganization of absorptive cell microvilli. Gastroenterology 106, 73-84.

26. Otte JM, Chen C, Brunke G, Kiehne K, Schmitz F, Folsch UR \& Herzig KH (2001) Mechanisms of lectin (phytohemagglutinin)-induced growth in small intestinal epithelial cells. Digestion 64, 169-178.

27. Baintner K, Jokab C, Gyori Z \& Kiss P (2000) Binding of the FITC-labelled lectins to the gastrointestinal epithelium of the rat. Pathol Oncol Res 6, 179-183.

28. Weinman MD, Allan CH, Trier JS \& Hagen SJ (1989) Repair of microvilli in the rat small intestine after damage with lectins contained in the red kidney bean. Gastroenterology 97, $1193-1204$

29. Giffen PS, Turton J, Andrews CM, Barrett P, Clarke CJ, Fung KW, Munday MR, Roman IF, Smyth R, Walshe K \& York MJ (2003) Markers of experimental acute inflammation in the Wistar Han rat with particular reference to haptoglobin and C-reactive protein. Arch Toxicol 77, 392-402.

30. Pusztai A (1993) Dietary lectins are metabolic signals for the gut and modulate immune and hormone functions. Eur J Clin Nutr 47, 691-699.

31. Oliveira JTA, Pusztai A \& Grant G (1988) Changes in organs and tissues induced by feeding of purified kidney bean (Phaseolus vulgaris) lectins. Nutr Res 8, 943-947.

32. Cummins AG, Labrooy JT \& Shearman DJ (1989) The effect of cyclosporin $\mathrm{A}$ in delaying maturation of the small intestine during weaning in the rat. Clin Exp Immunol 75, 451-456.

33. MacDonald TT \& Spenser JO (1988) Evidence that activated mucosal $\mathrm{T}$ cells play a role in the pathogenesis of enteropathy in human small intestine. J Exp Med 167, 1341-1349.

34. Cummins AG, Thompson FM \& Mayrhofer G (1991) Mucosal immune activation and maturation of the small intestine at weaning in the hypothymic (nude) rat. $J$ Pediatr Gastroenterol Nutr 12, 361-368.

35. Guy-Grand D \& Vassalli P (2002) Gut intraepithelial lymphocyte development. Curr Opin Immunol 14, 255-259.

36. Laky K, Lefrancois L, Lingenheld EG, Ishikawa H, Lewis JM, Olson S, Suzuki K, Tigelaar RE \& Puddington L (2000) Enterocyte expression of interleukin 7 induces development of $\gamma \delta \mathrm{T}$ cells and Peyers patches. J Exp Med 191, 1569-1580.

37. Golovkina TV, Shlomchik M, Hannum L \& Chervonsky A (1999) Organogenic role of B lymphocytes in mucosal immunity. Science 286, 1965-1968.

38. Dignass AU, Stow JL \& Babyatsky MW (1996) Acute epithelial injury in the rat small intestine in vivo is associated with expanded expression of transforming growth factor $\alpha$ and $\beta$. Gut 38, 687-693.

39. Kaouass M, Deloyer P, Gouders I, Peulen O \& Dandrifosse G (1997) Role of interleukin-1 $\beta$, interleukin-6, and TNF- $\alpha$ in intestinal maturation induced by dietary spermine in rats. Endocrine 6, 187-194.

40. Peulen O \& Dandrifosse G (2004) Spermine-induced maturation in Wistar rat intestine: a cytokine-dependent mechanism. J Pediatr Gastroenterol Nutr 38, 524-532. 